\title{
Differential expression of cyclooxygenase 2 in human colorectal cancer
}

\author{
J Dimberg, A Samuelsson, A Hugander, P Söderkvist
}

\begin{abstract}
Background-Experimental, clinical, and epidemiological studies have implicated mitogenic metabolites of arachidonic acid such as prostaglandin $E_{2}\left(P_{G E}\right)$ in colorectal carcinogenesis. Recently, cyclooxygenase 2 (COX-2) which catalyses the conversion of arachidonic acid to $\mathrm{PGE}_{2}$, has displayed increased levels in human colorectal cancer.

Aims-To evaluate whether there is differential COX-2 expression from different locations (caecum, ascending, transverse, descending, or sigmoid colon, and rectum) in human colorectal cancer.

Methods-Protein levels of COX-2 were determined by western blot analysis in tumours and adjacent normal mucosa of 39 patients with colorectal cancer.

Results-There was a notable overexpression of COX-2 protein in tumours located in the rectum $(p<0.001)$ compared with other locations in the colon. Rectal tumours revealed elevated COX-2 protein levels in $18 / 20$ cases compared with $4 / 19$ colonic cases. No association between enhanced COX-2 protein expression in tumour tissue and Dukes's stages was found.

Conclusions-Results suggest that the differential COX-2 expression may be due to differences in gene regulatory factors affecting COX-2 expression and/or reflect secondary changes in tumour progression which may have clinical implications.

(Gut 1999;45:730-732)
\end{abstract}

Keywords: cyclooxygenase 2; protein expression; human colorectal cancer

The cyclooxygenase (COX) isozymes COX-1 and COX-2 catalyse the conversion of arachidonic acid to eicosanoids, namely prostaglandins and thromboxanes via endoperoxides. ${ }^{1}$ Both isoforms are expressed in different cell types and tissues. COX-1 is a constitutively expressed isoform and is thought to carry out basal production of prostaglandins under homoeostatic conditions. COX-2 is an inducible isoform and can be induced in response to mitogenic agents, growth factors, lipopolysaccharides, and cytokines. Both isoforms are also responsible for the synthesis of prostaglandin $\mathrm{E}_{2}\left(\mathrm{PGE}_{2}\right)$, and there is some evidence for a correlation between increased levels of $\mathrm{PGE}_{2}$ and tumorigenesis. ${ }^{1-3}$

Epidemiological and rodent studies have documented a protective effect of nonsteroidal anti-inflammatory drugs (NSAIDs) in preventing colorectal cancer. NSAIDs inhibit COX-2 activity and $\mathrm{PGE}_{2}$ synthesis both in vitro and in vivo. ${ }^{4}$ Recently, increased COX-2 gene expression has been shown in human colorectal adenocarcinomas and in carcinogen induced rat colonic tumours. ${ }^{6-10}$ These observations suggest that abnormal production is an early event in the postinitiation phase of colon carcinogenesis. Moreover, previous studies have reported elevated levels of $\mathrm{PGE}_{2}$ in both human and rat colonic tumours. ${ }^{11-13}$ These findings suggest that COX-2 is responsible for the increased $\mathrm{PGE}_{2}$ production although no studies have indicated whether upregulation of COX-2 is a primary event or a consequence in the pathogenesis of colorectal cancer.

\section{Methods}

PATIENTS AND SAMPLING

Tissue samples were obtained from 39 patients undergoing surgical resections for primary colorectal adenocarcinomas diagnosed at the Department of Surgery, Ryhov County Hospital, Jönköping, Sweden. Sporadic tumours from 20 men and 19 women (mean age 73 years, range 25-93) were collected and classified into four stages according to the Dukes classification system; stage A $(n=4)$, stage B $(n=18)$, stage C $(n=12)$, and stage $D$ $(n=5)$. The tumours were localised in the caecum $(n=7)$, ascending colon $(n=5)$, transverse colon $(n=1)$, descending colon $(n=1)$, sigmoid colon $(n=5)$, and rectum $(n=20)$.

From each patient, tumour tissue and adjacent normal mucosa (about $10 \mathrm{~cm}$ from the tumour) was excised and collected. All tissues were immediately frozen and kept at $-70^{\circ} \mathrm{C}$ until analysis.

PROTEIN PREPARATION

Frozen tumour tissue and normal mucosa were thawed and homogenised in ice cold lysis buffer (160 mM NaCl, $10 \mathrm{mM}$ HEPES, $2 \mathrm{mM}$ $\mathrm{CaCl}_{2}, 0.5 \%$ sodium dodecyl sulphate (SDS), $0.5 \%$ Triton $\mathrm{X}-100,100 \mu \mathrm{g} / \mathrm{ml}$ phenylmethylsulphonyl fluoride, $1 \mu \mathrm{g} / \mathrm{ml}$ leupeptin, and 2 $\mu \mathrm{g} / \mathrm{ml}$ aprotinin) and placed on ice for $15 \mathrm{~min}-$ utes. Following clarification the lysis solution was centrifuged at $13000 \mathrm{~g}$ for 10 minutes. Protein content of homogenates was determined for each sample using the Lowry assay. ${ }^{14}$

Abbreviations used in this paper: APC, adenomatous polyposis coli; COX, cyclooxygenase; cPLA2, cytosolic phospholipase A2; NSAID, non-steroidal anti-inflammatory drug; $\mathrm{PGE}_{2}$, prostaglandin $\mathrm{E}_{2}$; PLA2-II, group II phospholipase A2; PPAR $\gamma$, peroxisome proliferator activated receptor; TCF/LEF, T cell factor/leucocyte enhancing factor. 


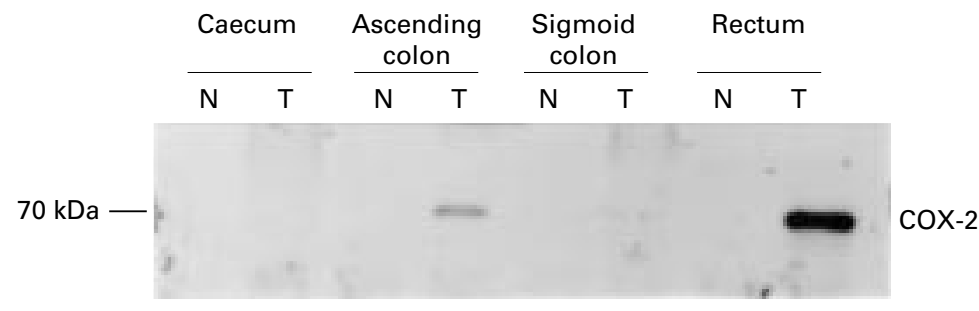

Figure 1 Western blot analysis of cyclooxygenase (COX) 2 protein expression in four representative specimens of human colorectal cancer. T, tumour tissue; $N$, matched normal mucosa from different locations. Molecular weight marker is indicated on the left.

SDS-PAGE AND WESTERN BLOTTING

Proteins $(60 \mu \mathrm{g})$ in the lysates were separated by electrophoresis using $8 \%$ SDS-PAGE (polyacrylamide gel electrophoresis). ${ }^{14}$ Separated proteins were transferred onto nitrocellulose membranes (Amersham) in a transblot electrophoretic transfer cell (Bio-Rad Laboratories).

IMMUNODETECTION

After transblotting the blots were blocked for two hours with $5 \%$ (wt/vol) non-fat dry milk dissolved in TTBS (1× TTBS: $20 \mathrm{mM}$ Tris, $150 \mathrm{mM} \mathrm{NaCl}, \mathrm{pH}$ 7.5, 0.1\% Tween 20). Blots were probed for two hours with an antihuman COX-2 antibody (Santa Cruz Biotechnology) diluted $1 / 250$ in TTBS containing 3\% (wt/vol) non-fat dry milk. After extensive washing in TTBS the blots were reincubated for one hour with horseradish peroxidase conjugated secondary antibody (Santa Cruz Biotechnology) diluted $1 / 4000$ in TTBS containing 3\% (wt/vol) non-fat dry milk. Blots were developed using an enhanced chemiluminescence (ECL) system (Amersham) and exposed to Hyperfilm ECL (Amersham). The optical density (OD) was measured by densitometry and the result is shown as relative expression (OD ratio) for tumour versus normal mucosa. All experiments were repeated in separate assays.

STATISTICAL ANALYSIS

Differences of COX-2 protein expression between rectum and colon in cancerous mucosa were examined by the $\chi^{2}$ (Pearson) analysis. Significance was set at $\mathrm{p}<0.001$. The data were subjected to computerised statistical analysis using SPSS (Statistical Products and Services Solutions) for Windows, version 6.1.

Table 1 Distribution pattern of cyclooxygenase 2 protein expression in tissue from 39 patients with colorectal adenocarcinoma

\begin{tabular}{lrrc}
\hline & & \multicolumn{2}{l}{$\begin{array}{l}\text { Relative expression } \\
\text { (tumour v normal mucosa) }\end{array}$} \\
\cline { 2 - 4 } Location & $n$ & $\leqslant 2$ & $>2$ (7-48) \\
\hline Rectum & 20 & 2 & 18 \\
Colon & 19 & 15 & 4 \\
$\quad$ Sigmoid & 5 & 4 & 1 \\
Descending & 1 & 1 & \\
Transverse & 1 & 1 & 2 \\
Ascending & 5 & 3 & 1 \\
Caecum & 7 & 6 & \\
\hline
\end{tabular}

${ }^{\star}$ Relative expression $>2$ was considered to represent enhanced levels.

The differences in cyclooxygenase 2 protein expression between rectum and colon were significant.

\section{Results}

Western blot analyses of COX-2 protein in human colorectal tumour tissue were pairwise related to normal mucosa from 39 examined surgical specimens. Probing of tissue proteins immobilised on nitrocellulose membranes with antihuman COX-2 antibody and subsequent quantification by densitometry showed substantially higher levels of COX-2 in cancerous mucosa from the rectum (fig 1 , table 1 ). In cancerous tissue of other parts, low or undetectable levels of COX-2 protein expression were usually found. The distribution pattern revealed a statistically significant prevalence $(\mathrm{p}<0.001)$ of upregulated COX-2 in cancerous tissue originating from rectum in relation to tumours of colonic origin. Table 1 summarises results of the western analyses. By means of densitometric evaluation a $7-48$ fold induction was found in $18 / 20$ rectal tumour tissues in relation to COX-2 protein expression in normal tissue. Only $2 / 20$ rectal tumours displayed no induction of COX-2, in contrast to $15 / 19$ for tumours with colonic localisation.

No association between enhanced COX-2 protein expression in tumour tissue and Dukes' stages was found (data not shown).

\section{Discussion}

Evidence that arachidonic acid and its metabolites may be mediators of tumorigenesis in colorectal carcinoma comes from experimental, clinical, and epidemiological studies in which inhibition of prostaglandin synthesis suppresses carcinogenesis. ${ }^{4}$ Group II phospholipase A2 (PLA2-II) and cytosolic phospholipase A2 (cPLA2) are enzymes which catalyse arachidonic acid release from the sn-2 position of glycerophospholipids and have been postulated to be the rate limiting step for $\mathrm{PGE}_{2}$ production. ${ }^{1}$ However, minor changes in PLA2-II and cPLA2 gene expression between tumour and non-cancerous tissue indicate that generation of arachidonic acid seems not to be the rate limiting step in $\mathrm{PGE}_{2}$ formation via COX $-2 .{ }^{15}$ Mutations of the human tumour suppressor gene adenomatous polyposis coli (APC) are prominent alterations in both sporadic and familial gastrointestinal tumours. ${ }^{16}$ It is interesting to note that it seems to be a link between the tumorigenic effect of APC mutations and arachidonic acid metabolism. Disruption of the COX-2 gene reduces the number of tumours in the Min mouse model of human familial adenomatous polyposis coli. ${ }^{17}$

Recent studies have indicated that enhanced expression of COX-2 and increased production of prostaglandins in intestinal epithelial cells protect the cells from apoptosis and stimulate production of angiogenic factors. ${ }^{18} 19$ In addition, the peroxisome proliferator activated receptor PPAR $\gamma$ is a transcription factor that has regulatory functions in differentiation of cells and has recently been shown to be overexpressed in human colon cancer. Diverse fatty acids and prostaglandins can bind to PPAR $\gamma$ and stimulate transcriptional activation of target genes. ${ }^{20}$ 
One essential factor linked to colon cancer is $\beta$ catenin which forms a complex with the APC protein. Mutations in APC and/or $\beta$ catenin gene(s) result in dissociation of the APC- $\beta$ catenin complex and excess free $\beta$ catenin binds to $\mathrm{TCF} / \mathrm{LEF}-1$ transcription factor which controls certain target genes-for example c-myc, probably contributing to colon tumorigenesis. $^{21}{ }^{22}$ One might speculate that $\beta$ catenin mediates activation of TCF/LEF-1 which, in turn, regulates COX-2 expression. This mechanism could link APC and/or $\beta$ catenin mutation with increased COX-2 transcription. However, a recent study has shown that activation of PPAR $\gamma$ in a human colon carcinoma cell line, HT-29, increased $\beta$ catenin protein levels but produced no effect on COX-2 expression. ${ }^{23}$

Several reports have shown that immunohistological staining of human colorectal tissue revealed COX-2 protein preferentially expressed in the cancer cells rather than infiltrating mononuclear cells or fibroblasts of the cancer stroma. ${ }^{79}$ In the present study we found a notable increase in COX-2 protein expression in tumour tissue compared with paired normal mucosa which is accompanied by increased mRNA levels determined by semiquantitative reverse transcriptase polymerase chain reaction. ${ }^{15}$ The enhanced COX-2 protein levels were preferentially localised to rectal tumours $(18 / 20)$ while only $4 / 19$ colonic tumours showed elevated COX-2. The explanation and interpretation of this finding is still uncertain but may be due to differences in genetic alterations in the tumour cells and/or differences in expression of COX-2 regulatory genes in the colon and rectum. Alternatively, our results may reflect secondary changes in tumour progression which differentially modulate the induction of COX-2 in different sites of the colon and rectum. A different pathway around COX-2 dependent oxidation of arachidonic acid to prostaglandins may be via another oxidase, for example, COX-1. Genetic analysis using COX-1 knockout mice can give further support to the proposal that COX-1 is a modifier for colorectal cancer.

Further investigations are necessary to determine the putative role of the COX-2 gene induction for tumour progression, apoptosis, and angiogenesis in human colorectal cancer. In conclusion, the present investigation showed that COX-2 protein is dramatically upregulated in a subset of human colorectal cancer and that the distribution pattern of overexpressed COX-2 protein in tumours showed a pronounced prevalence for the rectum.

This work was supported by grants from FORSS (nr F96-40) Linköping, Sweden and the County Council of Jönköping, Sweden.

1 Smith WL. Prostanoid biosynthesis and mechanism of action. Am f Physiol 1992;263:181-91

2 Lee SH, Soyoola E, Chanmugam P, et al. Selective expression of mitogen inducible cyclooxygenase in macrophages stimulated with lipopolysaccharide. $7 \mathrm{Biol}$ Chem 1992;267:25934-8.

3 O'Neill GP, Ford-Hutchinson AW. Expression of RNA for cyclooxygenase-1 and cyclooxygenase-2 in human tissues. FEBS Lett 1993;330:156-60.

4 DuBois RN, Smalley WE. Cyclooxygenase, NSAIDs and colorectal cancer. F Gastroenterol 1996;31:898-906.

5 Sheng H, Shao J, Kirkland SC, et al. Inhibition of human colon cancer cell growth by selective inhibition of colon cancer cell growth by selective inh

6 Eberhart CE, Coffey RJ, Radhika A, et al. Up-regulation of cyclooxygenase-2 gene expression in human colorectal
cy adenomas and adenocarcinomas. Gastroenterology 1994; 107:1183-8.

7 Sano H, Kawahito Y, Wilder RL, et al. Expression of cyclooxygenase-1 and -2 in human colorectal cancer. Cancer Res 1995;55:3785-9.

8 DuBois RN, Radhika A, Reddy BS, et al. Increased cyclooxygenase-2 levels in carcinogen-induced rat colonic tumors. Gastroenterology 1996;110:1259-62.

9 Kutchera W, Jones DA, Matsunami N, et al. Prostaglandin $\mathrm{H}$ synthase 2 is expressed abnormally in human colon cancer: evidence for a transcriptional effect. Proc Natl Acad Sci 1996;93:4816-20.

10 Tsujii M, Kawano S, DuBois RN. Cyclooxygenase-2 expression in human colon cancer cells increases metastatic potential. Proc Natl Acad Sci 1997;94:3336-40.

11 Yamaguchi A, Ishida T, Nishimura G, et al. Investigation of colonic prostaglandins in carcinogenesis in the rat colon. Dis Colon Rectum 1991;34:572-6.

12 Rigas B, Goldman IS, Levine L. Altered eicosanoid levels in human colorectal cancer. $\mathcal{F}$ Lab Clin Med 1993;122:51823.

13 Hendrickse CW, Kelly RW, Radley S, et al. Lipid peroxidation and prostaglandins in colorectal cancer. Br f Surg 1994;81:1219-23.

14 Bollag DM, Rozycki NW. Protein methods. New York: WileyLiss, 1996.

15 Dimberg J, Samuelsson A, Hugander A, et al. Gene expression of cyclooxygenase-2, group II and cytosolic phospholipase A2 in human colorectal cancer. Anticancer Res 1998;18:3283-7.

16 Nishisho I, Nakamura Y, Miyoshi Y, et al. Mutations of chromosome $5 \mathrm{q} 21$ genes in FAP and colorectal cance patients. Science 1991;253:665-9.

17 Oshima M, Dinchuk JE, Kargman SL, et al. Suppression of intestinal polyposis in $\mathrm{Apc}^{716}$ knockout mice by inhibition of cyclooxygenase 2 (COX-2). Cell 1996;87:803-9.

18 Tsujii M, DuBois RN. Alterations in cellular adhesion and apoptosis in epithelial cells overexpressing prostaglandin apoptosis in epithelial cells overexpressing prosta
endoperoxide synthase-2. Cell 1995;83:493-501.

19 Tsujii M, Kawano S, Tsuji S, et al. Cyclooxygenase regulates angiogenesis induced by colon cancer cells. Cell 1998;93: $705-16$

20 Sarraf P, Mueller E, Jones D, et al. Differentiation and reversal of malignant changes in colon cancer through PPAR $\gamma$. Nature Med 1998;4:1046-52.

21 Morin PJ, Sparks AB, Korinek V, et al. Activation of $\beta$-catenin-Tcf signaling in colon cancer by mutation in P-catenin or APC. Science 1997;275:1787-90.

$22 \mathrm{He}$ TC, Sparks AB, Rago C, et al. Identification of C-MYC as a target of the APC pathway. Science 1998;281:1509-12.

3 Lefebvre AM, Chen I, Desreumaux P, et al. Activation of the peroxisome proliferator activated receptor $\gamma$ promotes the tmice. Nature Med 1998;4:1053-7. 